\title{
Modified effectiveness and linear regression based models for heat exchangers under heat gain/loss to the environment
}

\author{
Gábor Géczi $^{(a)}$, Richárd Kicsiny*,(b) ${ }^{\text {,éter Korzenszky }}{ }^{(\mathrm{c})}$
}

(a) Department of Environmental and Building Engineering, Institute of Environmental Systems, Faculty of Mechanical Engineering, Szent István University, Páter K. u. 1., 2100 Gödöllö, Hungary

(b) Department of Mathematics, Institute of Environmental Systems, Faculty of Mechanical Engineering, Szent István University, Páter K. u. 1., 2100 Gödöllő, Hungary

(c) Department of Agricultural and Food Industrial Machines, Institute of Mechanics and Machinery, Faculty of Mechanical Engineering, Szent István University, Páter K. u. 1., 2100 Gödöllö, Hungary

*e-mail: Kicsiny.Richard@gek.szie.hu

\begin{abstract}
Developing mathematical models for describing heat exchanger outlet temperatures is of great importance for the practice, since heat exchangers are unavoidable elements in any applications, where heat transfer is needed between hydraulically separated fluid parts.

The conventional, well-tried physically-based E model (standing for the known effectivenessNTU approach) is recalled. This model assumes energy balance between the two sides of a heat exchanger (without any interaction with the environment). Based on studies in the literature, mathematical models with similar simplicity and usability to that of the E model, but under heat gain/loss to the environment, are still lacking in the field. This work intends to contribute to filling this gap with two proposed models, called ME and LR models.

Based on measured data, all three models are accurate enough for general engineering/modelling purposes, nevertheless, the partly physically-based, partly empirical ME model is more precise than the $\mathrm{E}$ model if the heat gain/loss to the environment is considerable, and the empirical (black-box type) LR model is more precise than both the $\mathrm{E}$ and ME models if the heat gain/loss is not negligible. Furthermore, the outlet temperatures can be explicitly expressed from the simple linear algebraic relations characterizing all models alike.
\end{abstract}

Keywords: Heat exchangers; Heat transfer with environment; Mathematical modelling; Outlet temperatures; Effectiveness; Linear regression

\section{Nomenclature}

$t:$ time, $\mathrm{s}$;

Time-dependent functions

$T_{a, i n}$ : inlet temperature of either the cold or the hot side of the heat exchanger, ${ }^{\circ} \mathrm{C}$;

$T_{a, \text { out }}$ : outlet temperature of either the cold or the hot side of the heat exchanger, ${ }^{\circ} \mathrm{C}$;

$T_{b, i n}$ : inlet temperature of either the cold or the hot side of the heat exchanger, ${ }^{\circ} \mathrm{C}$;

$T_{b, \text { out }}$ : outlet temperature of either the cold or the hot side of the heat exchanger, ${ }^{\circ} \mathrm{C}$;

$T_{c, i n}:$ inlet temperature of the cold side of the heat exchanger, ${ }^{\circ} \mathrm{C}$;

$T_{c, \text { out }}$ : outlet temperature of the cold side of the heat exchanger, ${ }^{\circ} \mathrm{C}$;

$T_{c, \text { out,meas }}$ : measured outlet temperature of the cold side of the heat exchanger, ${ }^{\circ} \mathrm{C}$;

$T_{c, \text { out }, \text { mod }}$ : modelled outlet temperature of the cold side of the heat exchanger, ${ }^{\circ} \mathrm{C}$;

$T_{h, i n}:$ inlet temperature of the hot side of the heat exchanger, ${ }^{\circ} \mathrm{C}$; 
$T_{h, \text { out }}$ : outlet temperature of the hot side of the heat exchanger, ${ }^{\circ} \mathrm{C}$;

$T_{h, \text { out meas }}$ : measured outlet temperature of the hot side of the heat exchanger, ${ }^{\circ} \mathrm{C}$;

$T_{h, \text { out } \text { mod }}$ : modelled outlet temperature of the hot side of the heat exchanger, ${ }^{\circ} \mathrm{C}$

\section{Constant parameters}

$A$ : area of heat transfer inside the heat exchanger, $\mathrm{m}^{2}$;

$A_{e}$ : exterior area of the heat exchanger to the environment, $\mathrm{m}^{2}$;

$c_{c}$ : specific heat capacity of the fluid in the cold side of the heat exchanger, $\mathrm{Jkg}^{-1} \mathrm{~K}^{-1}$;

$c_{c, c, i n}:$ constant coefficient to be identified in the LR model, -;

$c_{c, h, i n}$ : constant coefficient to be identified in the LR model, -;

$c_{h}$ : specific heat capacity of the fluid in the hot side of the heat exchanger, $\mathrm{Jkg}^{-1} \mathrm{~K}^{-1}$;

$c_{h, c, i n}$ : constant coefficient to be identified in the LR model, -;

$c_{h, h, i n}$ : constant coefficient to be identified in the LR model, -;

$m$ : constant coefficient to be identified in the ME model, -;

$T_{e}$ : temperature of the environment of the heat exchanger, ${ }^{\circ} \mathrm{C}$;

$u_{T}$ : uncertainty of the temperature measurements, ${ }^{\circ} \mathrm{C}$;

$v_{c}$ : flow rate in the cold side of the heat exchanger, $\mathrm{m}^{3} \mathrm{~s}^{-1}$;

$v_{h}$ : flow rate in the hot side of the heat exchanger, $\mathrm{m}^{3} \mathrm{~s}^{-1}$;

$\Delta t$ : time period between successive measurements on the heat exchanger, $\mathrm{s}$;

$\Phi$ : heat exchanger effectiveness (to be identified in the E model), -;

$\tau_{c}$ : time of flow from the inlet to the outlet of the cold side of the heat exchanger, $\mathrm{s}$;

$\tau_{h}$ : time of flow from the inlet to the outlet of the hot side of the heat exchanger, s;

$\rho_{c}$ : mass density of the fluid in the cold side of the heat exchanger, $\mathrm{kgm}^{-3}$;

$\rho_{h}$ : mass density of the fluid in the hot side of the heat exchanger, $\mathrm{kgm}^{-3}$

\section{Abbreviations}

E: effectiveness;

CPHE: compact (parallel) plate heat exchanger;

DPHE: double pipe heat exchanger;

LR: linear regression;

ME: modified effectiveness;

MLR: multiple linear regression;

ODE: ordinary differential equation;

PDE: partial differential equation

\section{Introduction}

It is very important to develop more and more precise mathematical models for describing the outlet temperatures of the cold and hot sides of heat exchangers, since these working components are essential in any practical applications, where heat transfer is required between hydraulically separated fluid parts (e.g. in (hydraulic) heating systems like central [1], district [2] or solar heating systems [3, 4], etc.).

Many modelling approaches like the ones based on the most commonly used [5] effectiveness-number of transfer units (effectiveness-NTU) method [6, 7] and the logarithmic mean temperature difference (LMTD) approach [8] assume energy balance between the two sides (that is between the fluids in the two sides) of a heat exchanger without any heat 
gain/loss to the environment. In [9], the LMTD is used to model the effect of a heat exchanger coil in a water storage tank. If the effectiveness of the heat exchanger is known, e.g. from identification or from auxiliary tables/diagrams published in the literature [8], the outlet temperatures can be explicitly expressed in a convenient way by means of the simple linear algebraic relations characterizing the effectiveness-NTU method. Often, the effect of the environment is really negligible because of structural reasons. For example, in case of coiled heat exchangers immersed in the cold fluid to be heated in a storage tank $[9,10]$ or compact parallel plate heat exchangers (CPHEs), where the exterior surface to the environment is much smaller than the surface of the heat transfer between the fluids [11]. More detailed but considerably more technical and hard to handle mathematical descriptions of the corresponding physical phenomena can be gained by means of ordinary differential equations (ODEs) or partial differential equations (PDEs). A system of ODEs models the temperature of the working fluids in [12] and systems of PDEs model the temperature distribution inside a heat exchanger in $[13,14]$. In [13], the PDEs for a unitary cell of parallel plate heat exchangers is solved analytically by means of eigenfunctions technique taking into account longitudinal and transverse wall conduction effects. Then the truncated form of the solution is compared numerically with another approximate solution (based on problem discretization) showing small difference. In [14], analytical expression is derived with respect to the NTU values of counter flow heat exchangers under longitudinal conduction in both the fluid separating and the outer walls. A special, thermo-economic approach can be found in [15] corresponding to a single pass, counter flow heat exchanger model. The objective function, depending on the effectiveness and the NTU, considers the current heat transfer rate per unit area as well as the exergy change (due to the heat transfer between the fluids) and the investment costs.

Many times, the heat gain/loss to the environment cannot be neglected for the sake of satisfactory modelling. Such cases are those, for example, when the size of the exterior surface of the heat exchanger is similar to that of the heat transfer between the fluids. See e.g. double pipe heat exchangers (DPHEs) in this regard. This type of heat exchangers has high priority in chemical, food, oil and gas industries [16]. The ODE models of [17, 18,19] consider the effect of the environment. In [17, 19], expressions for the effectiveness-NTU relation of parallel flow heat exchangers are derived analytically with respect to uniform external heat flux. In [18], a three-fluid heat exchanger (basically in tubular configuration) is investigated. The equations are solved both analytically and with finite element method. The analytical solution of a PDE model can be found in [20] dealing also with the effect of the environment as well as the longitudinal heat conduction in the separating wall inside the heat exchanger. Because of the often complex heat processes encountered in real circumstances, realistic (but expertise demanding) simulation programs (like computational fluid dynamics (CFD) codes) are also needed for the mathematical modelling of different kinds of heat exchangers. In [11] and [10], the outlet temperatures of a parallel plate heat exchanger at different operating conditions and the heat transfer rate induced by natural convection over the outer surface of a coiled heat exchanger in a water storage tank are modelled by means of CFD codes. Further simulation software products for plate-fin and coiled-wound heat exchangers are mentioned in [5]. Naturally, real life experiments remain the most direct (but likely the most arduous and expensive) method for revealing heat exchanger processes. In [21] and [22], characteristic diagrams of DPHEs are gained from measured data.

Physically-based (or white-box) models have been discussed above, which represent exact physical laws. If these laws are not known or they are not taken into account, experienced or measured correlations between the inputs and outputs of the studied system can still be expressed by means of empirical (or black-box) models. Based on former experiences on solar collectors [23], pipes [24] and storage tanks [25], MLR based models are likely the simplest possible (black-box) models (because of the simple linear algebraic relations), which can still reach a very good accuracy. Accordingly, in the Conclusion of the latter two 
references, it was suggested to work out MLR based models for different working components in hydraulic heating systems. In the present paper, an MLR based model (called LR model in short) is proposed to predict the outlet temperatures of heat exchangers, generally.

Based on further studies in the literature, mathematical models with similar (linear, algebraic) simplicity to that of the conventional effectiveness-NTU model (called E model below for simplicity), under heat gain/loss to the environment, are still lacking in the field. This work intends to contribute to filling this gap with the ME and LR models. The main contributions, relating to heat exchangers, are the following in more details.

1. The ME model is proposed (and validated) as the modified version of the well-tried and frequently used, physically-based E model. Based on measured data, this partly physicallybased, partly empirical model is more precise than the E model if the heat transfer between the heat exchanger and the environment is considerable.

2. The completely new LR model is proposed (and validated) as a simple MLR based blackbox model. This empirical model is always more precise than the E and ME models if the heat transfer between the heat exchanger and the environment is not negligible.

It is worth noting in advance that the ME and LR models are the same convenient to use as the E model, since the outlet temperatures can be explicitly expressed from the corresponding simple linear algebraic relations.

The paper is organized in the following way: Section 2 serves with general features on the measurements and modelling of heat exchangers with respect to the whole study. In Section 3, the $\mathrm{E}$ and ME models are given along with their identification and validation on the basis of measured data. The LR model is worked out, identified and validated in Section 4. Section 5 presents the detailed comparison of the E, ME and LR models in view of accuracy completed with the discussion of the results. Furthermore, the LR model is compared with another linear model published in [26], based on which the advantages of the LR model are shown. In Section 6, summarizing conclusions can be found with recommendations on future research. The Matlab software [27] is applied in this work to execute the required calculations.

\section{General features on measurements and modelling}

The outlet temperatures $T_{c, \text { out }}$ and $T_{h, \text { out }}$ of a heat exchanger (see Fig. 1) are modelled in this work according to the E, ME and LR models in case of constant $v_{c}$ and $v_{h}$ flow rate values.

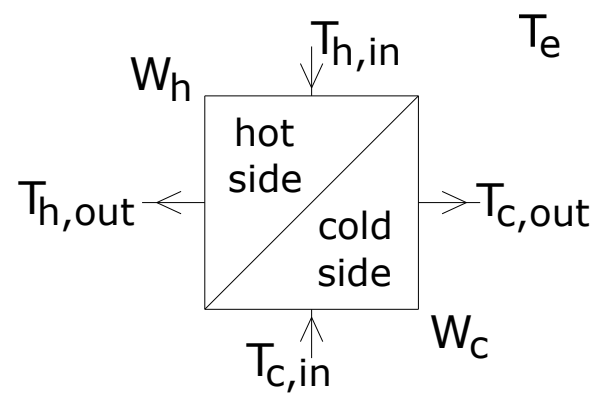

Fig. 1. General scheme of the studied heat exchangers

Specifically, at any modelled time $t, T_{c, \text { out }}(t)$ and $T_{h, \text { out }}(t)$ are determined as a function of the inlet temperatures corresponding to an earlier time, that is, $T_{c, \text { in }}\left(t-\tau_{c}\right)$ and $T_{h, \text { out }}\left(t-\tau_{h}\right)$, where $\tau_{c}$ and $\tau_{h}$ are the time delays with respect to the time of flow in the cold and hot side, respectively. More precisely, because of technical reasons, $\tau_{c}$ and $\tau_{h}$ are rounded up according to the time period of the measurements $\Delta t$. If $t-\tau_{c}$ or $t-\tau_{h}$ is less than 0 (at the 
beginning of the modelled time period), $T_{c, i n}(0)$ or $T_{h, i n}(0)$ is used instead of $T_{c, i n}\left(t-\tau_{c}\right)$ or $T_{h, i n}\left(t-\tau_{h}\right)$, respectively.

Two measured counter-flow heat exchangers, at the Szent István University (SZIU), Gödöllő, Hungary, of different kinds are used for the identification and the validation of the models. See Fig. 2 for the general schemes and Table 1 for the parameter values of them.
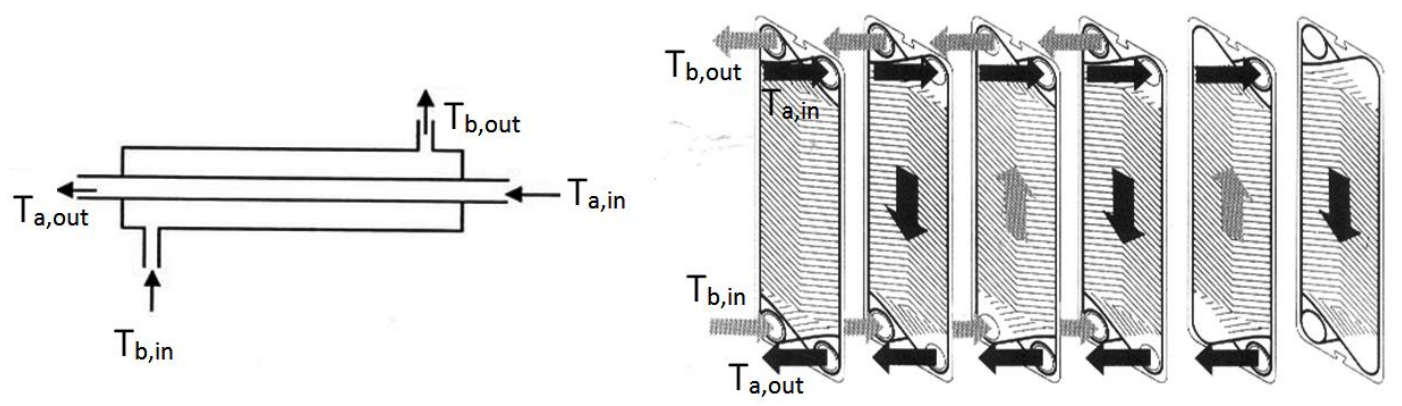

Fig. 2. General schemes of the measured DPHE (left) and CPHE (right) [28, 29]

Table 1. Parameter values of the heat exchangers with respect to the models

\begin{tabular}{|c|c|c|c|c|c|c|c|c|c|}
\hline & \multicolumn{6}{|c|}{ DPHE } & \multirow{2}{*}{\multicolumn{3}{|c|}{ CPHE }} \\
\hline & \multicolumn{3}{|c|}{ Outer pipe hot } & \multicolumn{3}{|c|}{ Outer pipe cold } & & & \\
\hline & $\mathrm{E}$ & $\mathrm{ME}$ & LR & $\mathrm{E}$ & $\mathrm{ME}$ & LR & $\mathrm{E}$ & $\mathrm{ME}$ & LR \\
\hline$A, \mathrm{~m}^{2}$ & \multicolumn{6}{|c|}{0.03} & \multicolumn{3}{|c|}{2} \\
\hline$A_{e}, \mathrm{~m}^{2}$ & \multicolumn{6}{|c|}{0.1} & \multicolumn{3}{|c|}{0.24} \\
\hline$c_{c}, \mathrm{Jkg}^{-1} \mathrm{~K}^{-1}$ & \multicolumn{2}{|c|}{4200} & - & \multicolumn{2}{|c|}{4200} & - & \multicolumn{2}{|c|}{4200} & - \\
\hline $\begin{array}{l}c_{c, c, i n},- \\
\text { (identified) }\end{array}$ & \multicolumn{2}{|c|}{ - } & 0.214 & \multicolumn{2}{|c|}{ - } & 0.522 & \multicolumn{2}{|c|}{ - } & 0.373 \\
\hline $\begin{array}{l}c_{c, h, i n},- \\
\text { (identified) }\end{array}$ & \multicolumn{2}{|c|}{ - } & 0.289 & \multicolumn{2}{|c|}{ - } & 0.258 & \multicolumn{2}{|c|}{ - } & 0.648 \\
\hline$c_{h}, \mathrm{Jkg}^{-1} \mathrm{~K}^{-1}$ & \multicolumn{2}{|c|}{4200} & - & \multicolumn{2}{|c|}{4200} & - & \multicolumn{2}{|c|}{3623} & - \\
\hline $\begin{array}{l}c_{h, c, i n},- \\
\text { (identified) }\end{array}$ & \multicolumn{2}{|c|}{-} & 0.484 & \multicolumn{2}{|c|}{-} & 0.185 & \multicolumn{2}{|c|}{ - } & 0.413 \\
\hline $\begin{array}{l}c_{h, h, i n},- \\
\text { (identified) }\end{array}$ & \multicolumn{2}{|c|}{ - } & 0.719 & \multicolumn{2}{|c|}{-} & 0.896 & \multicolumn{2}{|c|}{ - } & 0.594 \\
\hline $\begin{array}{l}m,- \\
\text { (identified) }\end{array}$ & 1 & 1.27 & - & 1 & 0.93 & - & 1 & 1 & - \\
\hline$T_{e},{ }^{\circ} \mathrm{C}$ & \multicolumn{3}{|c|}{4.6} & \multicolumn{3}{|c|}{11.2} & \multicolumn{3}{|c|}{28.3} \\
\hline$v_{c}, \mathrm{~m}^{3} \mathrm{~h}^{-1}$ & \multicolumn{2}{|c|}{0.02} & - & \multicolumn{2}{|c|}{0.047} & - & \multicolumn{2}{|c|}{0.55} & - \\
\hline$v_{h}, \mathrm{~m}^{3} \mathrm{~h}^{-1}$ & \multicolumn{2}{|c|}{0.024} & - & & & - & & & - \\
\hline$\Delta t, \mathrm{~s}$ & & 10 & & & 10 & & & 60 & \\
\hline $\begin{array}{l}\Phi,- \\
\text { (identified) }\end{array}$ & & & - & & & - & & & - \\
\hline$\tau_{c}, \mathrm{~s}$ & & 20 & & & 50 & & & 60 & \\
\hline$\tau_{h}, \mathrm{~s}$ & & 90 & & & 10 & & & 60 & \\
\hline$\rho_{c}, \mathrm{kgm}^{-3}$ & & & - & & & - & & & - \\
\hline$\rho_{h}, \mathrm{kgm}^{-3}$ & & & - & & & - & & & - \\
\hline
\end{tabular}


The first monitored heat exchanger is a DPHE applied in two cases, that is when the hot fluid is in the outer pipe and when the hot fluid is in the inner pipe. Technically, this heat exchanger consists of two identical horizontal parts (which can be seen in Fig. 2) connected with flexible pipes. The DPHE is used in controlled test conditions with measured and set up inputs. More particularly, $T_{h, i n}$ is set by means of a PHYWE type thermostat with a 6-litre water bath. The second monitored heat exchanger is a CPHE used in real operation as a part of a solar heating system installed at the campus of the SZIU [30]. Both heat exchangers are studied only if both sides are circulated (by means of pumps), otherwise the performance analysis of a heat exchanger is not relevant. The time period of the measurements $\Delta t$ is $10 \mathrm{~s}$ and $1 \mathrm{~min}$ in case of the DPHE and the CPHE, respectively. $T_{c, i n}, T_{h, i n}, v_{c}$ and $v_{h}$ are measured as well as $T_{c, \text { out }}$ and $T_{h, \text { out }}$ for comparison and $T_{e}$ as supplementary information. The precision of the measuring devices is $\pm 1{ }^{\circ} \mathrm{C}$ in case of the temperature sensors (type $\mathrm{K}$ thermocouple for the DPHE and LM 335 type sensor for the CPHE), $0.005 \mathrm{~m}^{3} \mathrm{~h}^{-1}$ in case of the flow meter of the DPHE (Unirota 96-150-719 type flow meter) $0.02 \mathrm{~m}^{3} \mathrm{~h}^{-1}$ in case of the flow meter of the CPHE (Schlumberger Flostar-M type flow meter).

The identification and the validation are carried out based on different measured data in case of both heat exchangers. 18 and 17 measured time points throughout the whole investigated temperature range $\left(4-90{ }^{\circ} \mathrm{C}\right)$ are used in the identification of the DPHE in the case when the hot fluid is in the outer pipe and when it is in the inner pipe, respectively. Similarly, 622 and 741 measured time points (different from the ones of the identification) are used in the validation of the DPHE, respectively. The data during the time of (fluid) circulation on four measured days (8 June, 24 June, 28 June and 2 July, 2012) are used in the identification of the CPHE. Similarly, the data of 56 measured days (from 3 July to 31 August, 2012) are used in the validation of the CPHE. The values of $v_{c}$ and $v_{h}$ (which are kept constant) are average measured flow rate values with respect to the measured time points of the whole identification.

The modelled outlet temperatures are calculated with the models for each measured time then the modelled and measured values of the outlet temperatures can be directly compared (that is $T_{c, \text { out mod }}$ can be compared with $T_{c, \text { out,meas }}$ and $T_{h, \text { out,mod }}$ can be compared with $\left.T_{h, \text { out,meas }}\right)$. The following indices (corresponding to the time period, which is currently investigated) are used below in the comparison: the average of error is the time average of $\left(T_{c, \text { out,mod }}-T_{c, \text { out,meas }}\right)$ in case of the cold side and the time average of $\left(T_{h, \text { out,mod }}-T_{h, \text { out,meas }}\right)$ in case of the hot side of the heat exchanger, the average of absolute error is the time average of the absolute value $\left|T_{c, \text { out } \text { mod }}-T_{c, \text { out,meas }}\right|$ in case of the cold side and the time average of $\left|T_{h, \text { out }, \text { mod }}-T_{h, \text { out,meas }}\right|$ in case of the hot side. The average of absolute error is determined also in \% dividing it by the (positive) difference between the maximal and minimal value of $T_{c, \text { out,meas }}$ or $T_{h, \text { out,meas }}$ (according to the current side of the heat exchanger).

\section{E and ME models}

The heat capacity rate is defined as $W_{c}=c_{c} v_{c} \rho_{c}$ for the cold side and $W_{h}=c_{h} v_{h} \rho_{h}$ for the hot side of a heat exchanger. Eqs. (1a) and (1b) describe the E model for heat exchangers if $W_{c}<$ $W_{h}$. This condition always holds in case of the experiments of the present study.

$$
\begin{aligned}
& T_{c, \text { out }}(t)-T_{c, \text { in }}\left(t-\tau_{c}\right)=\Phi\left(T_{h, \text { in }}\left(t-\tau_{h}\right)-T_{c, \text { in }}\left(t-\tau_{c}\right)\right), \\
& W_{c}\left(T_{c, \text { out }}(t)-T_{c, \text { in }}\left(t-\tau_{c}\right)\right)=W_{h}\left(T_{h, \text { in }}\left(t-\tau_{h}\right)-T_{h, \text { out }}(t)\right)
\end{aligned}
$$

Eqs. (2a) and (2b) describe the ME model for heat exchangers generally if $W_{c}<W_{h}$. 


$$
\begin{gathered}
T_{c, \text { out }}(t)-T_{c, \text { in }}\left(t-\tau_{c}\right)=\Phi\left(T_{h, \text { in }}\left(t-\tau_{h}\right)-T_{c, \text { in }}\left(t-\tau_{c}\right)\right), \\
m W_{c}\left(T_{c, \text { out }}(t)-T_{c, \text { in }}\left(t-\tau_{c}\right)\right)=W_{h}\left(T_{h, \text { in }}\left(t-\tau_{h}\right)-T_{h, \text { out }}(t)\right)
\end{gathered}
$$

The difference is the coefficient $m$ in the ME model, which is not used in the E model according to that the $\mathrm{E}$ model assumes that the two sides of the heat exchanger are in perfect energy balance. The coefficient $m$ expresses that the heat power of the two sides may be unbalanced to some extent, for example, because of different heat loss (or heat gain) to the environment. In particular, if $m>1$ then $T_{h, i n}\left(t-\tau_{h}\right)-T_{h, \text { out }}(t)$ should be greater, that is more heat power is needed in the hot side, than in case of perfect energy balance, which means that the hot side has some heat loss to the environment (more than that of the cold side). Accordingly, if $m<1$ then the cold side has some heat gain from the environment (more than that of the hot side). $m=1$ is the case of perfect energy balance between the two sides.

Since the measuring uncertainty of the temperatures is known, $u_{T}=1{ }^{\circ} \mathrm{C}$ (which means $\pm 1{ }^{\circ} \mathrm{C}$ precision of the measuring devices), the uncertainty of the modelled $T_{c, \text { out }}$ and $T_{h, \text { out }}$ temperatures can be determined with Eqs. (3a) and (3b), based on the well-known relation on the propagation of error [31], in case of both the E and ME models.

$$
\begin{aligned}
& u_{c, \text { out }}=\sqrt{\left(\frac{\partial T_{c, \text { out }}(t)}{\partial T_{c, \text { in }}\left(t-\tau_{c}\right)} u_{T}\right)^{2}+\left(\frac{\partial T_{c, \text { out }}(t)}{\partial T_{h, \text { in }}\left(t-\tau_{h}\right)} u_{T}\right)^{2}}, \\
& u_{h, \text { out }}=\sqrt{\left(\frac{\partial T_{h, \text { out }}(t)}{\partial T_{c, \text { in }}\left(t-\tau_{c}\right)} u_{T}\right)^{2}+\left(\frac{\partial T_{h, \text { out }}(t)}{\partial T_{h, \text { in }}\left(t-\tau_{h}\right)} u_{T}\right)^{2}}
\end{aligned}
$$

The partial derivatives in Eqs. (3a) and (3b) can be derived from the relations (1a) and (1b) in case of the E model and from the relations (2a) and (2b) in case of the ME model. The results for both models can be found in Table 2 .

Table 2. Uncertainty values of the models

\begin{tabular}{|c|c|c|c|c|c|c|}
\hline \multirow{2}{*}{} & \multicolumn{5}{|c|}{ DPHE } & \multicolumn{2}{c|}{ CPHE } \\
\cline { 2 - 6 } & \multicolumn{2}{|c|}{ Outer pipe hot } & \multicolumn{2}{c|}{ Outer pipe cold } & \multicolumn{1}{c|}{} \\
\cline { 2 - 6 } & $u_{c, \text { out }}$ & $u_{h, \text { out }}$ & $u_{c, \text { out }}$ & $u_{h, \text { out }}$ & $u_{c, \text { out }}$ & $u_{h, \text { out }}$ \\
\hline $\mathrm{E}$ & $0.8^{\circ} \mathrm{C}$ & $0.82^{\circ} \mathrm{C}$ & $0.81^{\circ} \mathrm{C}$ & $0.94^{\circ} \mathrm{C}$ & $0.76^{\circ} \mathrm{C}$ & $0.72{ }^{\circ} \mathrm{C}$ \\
\hline $\mathrm{ME}$ & $0.8^{\circ} \mathrm{C}$ & $0.79^{\circ} \mathrm{C}$ & $0.81^{\circ} \mathrm{C}$ & $0.88^{\circ} \mathrm{C}$ & $0.76^{\circ} \mathrm{C}$ & $0.72^{\circ} \mathrm{C}$ \\
\hline $\mathrm{LR}$ & $\mathbf{0 . 3 6}^{\circ} \mathbf{C}$ & $0.87^{\circ} \mathrm{C}$ & $\mathbf{0 . 5 8}{ }^{\circ} \mathbf{C}$ & $0.91^{\circ} \mathrm{C}$ & $0.75^{\circ} \mathrm{C}$ & $0.72^{\circ} \mathrm{C}$ \\
\hline
\end{tabular}

\section{Remark}

If $W_{c}<W_{h}$, Eq. (1a) (the same as Eq. (2a)) should be substituted with $T_{h, \text { in }}\left(t-\tau_{h}\right)-T_{h, \text { out }}(t)=\Phi\left(T_{h, \text { in }}\left(t-\tau_{h}\right)-T_{c, \text { in }}\left(t-\tau_{c}\right)\right)$.

\subsection{Identification}

In the identification of the E and ME models, $T_{c, \text { out, mod }}(t)$ is determined from Eq. (1a) (or Eq. (2a), which is the same) in case of both models then $T_{h, \text { out mod }}(t)$ is determined from Eq. (1b) in case of the E model and from Eq. (2b) in case of the ME model. For these calculations, the measured values of $T_{c, i n}\left(t-\tau_{c}\right)$ and $T_{h, i n}\left(t-\tau_{h}\right)$ are fed into the equations, but the unknown parameters $\Phi$ and $m$ should be identified. In the first step of the identification, the value of $\Phi$ is set for both models such that the mean \% value of the average of absolute error with respect 
to $T_{c, \text { outmod }}$ and $T_{c, \text { out,meas }}$ for the whole identification is minimal (e.g. $1.1 \%$ with both models for the CPHE, see Table 5). Then (with this identified $\Phi$ value) the value of $m$ is set for the ME model in such a way that the mean $\%$ value of the average of absolute error with respect to $T_{h, \text { out mod }}$ and $T_{h, \text { out,meas }}$ for the whole identification is minimal (e.g. $5.4 \%$ with the $\mathrm{E}$ model and $1.3 \%$ with the ME model for the DPHE if the outer pipe is hot, see Table 4). In this exact way, $\Phi$ and $m$ are not optional but unambiguously determined. In fact, they still depend on the measured values of the time period for the identification, nevertheless, with a given data base for the identification, they do not depend on the subjective thoughts of the user. Furthermore, the possible measurement-dependent (slight) deviation can be minimized with satisfactorily much data for the identification. The resulted (identified) values of $\Phi$ and $m$ can be found in Table 1.

Henceforth, the models with identified $\Phi$ and $m$ are applied to model the outlet temperatures throughout the whole time of the identification. Tables 3, 4 and 5 present the indices of comparison with respect to the modelled and measured results.

Table 3. $R^{2}$ values of the models for the identification

\begin{tabular}{|c|c|c|c|c|c|c|}
\hline \multirow{2}{*}{} & \multicolumn{4}{|c|}{ DPHE } & \multicolumn{2}{c|}{ CPHE } \\
\cline { 2 - 6 } & \multicolumn{3}{|c|}{ Outer pipe hot } & \multicolumn{2}{c|}{ Outer pipe cold } & \multicolumn{2}{c|}{} \\
\cline { 2 - 6 } & $T_{c, \text { out }}$ & $T_{h, \text { out }}$ & $T_{c, \text { out }}$ & $T_{h, \text { out }}$ & $T_{c, \text { out }}$ & $T_{h, \text { out }}$ \\
\hline E & 0.9911 & 0.9985 & 0.9946 & 0.9997 & 0.9919 & 0.9951 \\
\hline ME & 0.9911 & 0.9979 & 0.9946 & 0.9997 & 0.9919 & 0.9951 \\
\hline LR & 0.9913 & 0.9988 & 0.9906 & 0.9997 & 0.9938 & 0.9904 \\
\hline
\end{tabular}


Table 4. Average of error and average of absolute error values with the DPHE

\begin{tabular}{|c|c|c|c|c|c|c|}
\hline & & & & $\mathrm{E}$ & ME & LR \\
\hline & & & Average of error & $0.16^{\circ} \mathrm{C}$ & $0.16^{\circ} \mathrm{C}$ & $0.02{ }^{\circ} \mathrm{C}$ \\
\hline & & $T_{c, \text { out }}$ & Average of absolute error & $\begin{array}{c}0.83{ }^{\circ} \mathrm{C}, \\
4.2 \%\end{array}$ & $\begin{array}{c}0.83{ }^{\circ} \mathrm{C} \\
4.2 \%\end{array}$ & $\begin{array}{c}0.47{ }^{\circ} \mathrm{C}, \\
2.4 \%\end{array}$ \\
\hline & Identification & & Average of error & $2.70^{\circ} \mathrm{C}$ & $0.23^{\circ} \mathrm{C}$ & $-0.07^{\circ} \mathrm{C}$ \\
\hline$\frac{\overrightarrow{0}}{0}$ & & $T_{h, \text { out }}$ & Average of absolute error & $\begin{array}{c}2.70{ }^{\circ} \mathrm{C}, \\
5.4 \%\end{array}$ & $\begin{array}{c}0.66^{\circ} \mathrm{C} \\
1.3 \%\end{array}$ & $\begin{array}{c}0.41{ }^{\circ} \mathrm{C}, \\
0.8 \%\end{array}$ \\
\hline $\bar{z}$ & & & Average of error & $-0.10^{\circ} \mathrm{C}$ & $-0.10^{\circ} \mathrm{C}$ & $0^{\circ} \mathrm{C}$ \\
\hline$\stackrel{\mathscr{0}}{3}$ & & $T_{c, \text { out }}$ & Average of absolute error & $\begin{array}{c}1.05{ }^{\circ} \mathrm{C} \text {, } \\
4.9 \%\end{array}$ & $\begin{array}{c}1.05^{\circ} \mathrm{C} \\
4.9 \%\end{array}$ & $\begin{array}{c}0.61{ }^{\circ} \mathrm{C}, \\
\mathbf{2 . 8 \%}\end{array}$ \\
\hline & re & & Average of error & $3.23{ }^{\circ} \mathrm{C}$ & $0.26^{\circ} \mathrm{C}$ & $0^{\circ} \mathrm{C}$ \\
\hline & & $T_{h, \text { out }}$ & Average of absolute error & $\begin{array}{c}3.23{ }^{\circ} \mathrm{C}, \\
5.9 \%\end{array}$ & $\begin{array}{c}0.66^{\circ} \mathrm{C} \\
1.2 \%\end{array}$ & $\begin{array}{c}0.55^{\circ} \mathrm{C}, \\
\mathbf{1 . 0 \%}\end{array}$ \\
\hline & & & Average of error & $0.23{ }^{\circ} \mathrm{C}$ & $0.23^{\circ} \mathrm{C}$ & $-0.08^{\circ} \mathrm{C}$ \\
\hline & & $T_{c, \text { out }}$ & Average of absolute error & $\begin{array}{c}0.79^{\circ} \mathrm{C}, \\
5.8 \%\end{array}$ & $\begin{array}{c}0.79^{\circ} \mathrm{C}, \\
5.8 \%\end{array}$ & $\begin{array}{c}0.36^{\circ} \mathrm{C}, \\
2.6 \%\end{array}$ \\
\hline & $\mathrm{Id}$ & & Average of error & $-0.23^{\circ} \mathrm{C}$ & $0.03{ }^{\circ} \mathrm{C}$ & $-0.04{ }^{\circ} \mathrm{C}$ \\
\hline $\begin{array}{l}\overline{8} \\
0 \\
0\end{array}$ & & $T_{h, \text { out }}$ & Average of absolute error & $\begin{array}{c}0.35{ }^{\circ} \mathrm{C} \\
0.7 \% \\
\end{array}$ & $\begin{array}{c}0.25^{\circ} \mathrm{C} \\
0.5 \% \\
\end{array}$ & $\begin{array}{c}0.23{ }^{\circ} \mathrm{C}, \\
0.5 \%\end{array}$ \\
\hline 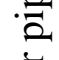 & & & Average of error & $-0.01^{\circ} \mathrm{C}$ & $-0.01{ }^{\circ} \mathrm{C}$ & $0.01{ }^{\circ} \mathrm{C}$ \\
\hline$\stackrel{\bar{\Xi}}{\Xi}$ & $\mathbf{y}+2$ & $T_{c, \text { out }}$ & Average of absolute error & $\begin{array}{c}0.84{ }^{\circ} \mathrm{C}, \\
6.0 \%\end{array}$ & $\begin{array}{c}0.84{ }^{\circ} \mathrm{C} \\
6.0 \%\end{array}$ & $\begin{array}{c}0.37{ }^{\circ} \mathrm{C}, \\
\mathbf{2 . 6 \%}\end{array}$ \\
\hline & valluation & & Average of error & $-0.2{ }^{\circ} \mathrm{C}$ & $0.13{ }^{\circ} \mathrm{C}$ & $0^{\circ} \mathrm{C}$ \\
\hline & & $T_{h, \text { out }}$ & Average of absolute error & $\begin{array}{c}0.30{ }^{\circ} \mathrm{C}, \\
0.6 \%\end{array}$ & $\begin{array}{c}0.34{ }^{\circ} \mathrm{C} \\
0.7 \%\end{array}$ & $\begin{array}{c}0.19{ }^{\circ} \mathrm{C}, \\
0.4 \%\end{array}$ \\
\hline
\end{tabular}


Table 5. Average of error and average of absolute error values with the CPHE

\begin{tabular}{|c|c|c|c|c|c|}
\hline & & & & $\mathrm{E} / \mathrm{ME}$ & LR \\
\hline \multirow{6}{*}{ 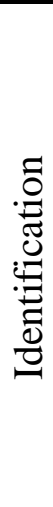 } & \multirow{4}{*}{28 June, 2012} & \multirow[b]{2}{*}{$T_{c, \text { out }}$} & Average of error & $-0.03^{\circ} \mathrm{C}$ & $-0.19^{\circ} \mathrm{C}$ \\
\hline & & & Average of absolute error & $\begin{array}{c}0.39^{\circ} \mathrm{C} \\
1.0 \%\end{array}$ & $\begin{array}{c}0.45{ }^{\circ} \mathrm{C}, \\
1.2 \%\end{array}$ \\
\hline & & \multirow[b]{2}{*}{$T_{h, \text { out }}$} & Average of error & $0.29^{\circ} \mathrm{C}$ & $0.43{ }^{\circ} \mathrm{C}$ \\
\hline & & & Average of absolute error & $\begin{array}{c}0.56^{\circ} \mathrm{C}, \\
1.5 \%\end{array}$ & $\begin{array}{c}0.76^{\circ} \mathrm{C}, \\
2.0 \%\end{array}$ \\
\hline & \multirow{2}{*}{$\begin{array}{l}\text { Mean } \% \text { value for } \\
\text { the whole } \\
\text { identification (four } \\
\text { days) }\end{array}$} & $T_{c, \text { out }}$ & Average of absolute error & $1.1 \%$ & $1.1 \%$ \\
\hline & & $T_{h, \text { out }}$ & Average of absolute error & $1.5 \%$ & $1.6 \%$ \\
\hline \multirow{6}{*}{ } & \multirow{4}{*}{3 August, 2012} & \multirow[b]{2}{*}{$T_{c, \text { out }}$} & Average of error & $0.02{ }^{\circ} \mathrm{C}$ & $0.2^{\circ} \mathrm{C}$ \\
\hline & & & Average of absolute error & $\begin{array}{c}0.4^{\circ} \mathrm{C}, \\
0.9 \%\end{array}$ & $\begin{array}{c}0.35{ }^{\circ} \mathrm{C}, \\
0.8 \%\end{array}$ \\
\hline & & \multirow[b]{2}{*}{$T_{h, \text { out }}$} & Average of error & $-0.11^{\circ} \mathrm{C}$ & $0.11^{\circ} \mathrm{C}$ \\
\hline & & & Average of absolute error & $\begin{array}{c}0.56^{\circ} \mathrm{C} \\
1.2 \%\end{array}$ & $\begin{array}{c}0.65{ }^{\circ} \mathrm{C}, \\
1.4 \%\end{array}$ \\
\hline & \multirow{2}{*}{$\begin{array}{l}\text { Mean \% value for } \\
\text { the whole } \\
\text { validation } \\
\text { (3 July - } 31 \\
\text { August) }\end{array}$} & $T_{c, \text { out }}$ & Average of absolute error & $1.5 \%$ & $1.5 \%$ \\
\hline & & $T_{h, \text { out }}$ & Average of absolute error & $3.0 \%$ & $3.3 \%$ \\
\hline
\end{tabular}

Table 3 contains the $R^{2}$ (square of correlation coefficient) values of the models for the identification. Table 4 shows that the average of absolute error is $4.2 \%$ for $T_{c, o u t}$ with the $\mathrm{E}$ and ME models, $5.4 \%$ for $T_{h, \text { out }}$ with the E model and $1.3 \%$ for $T_{h, \text { out }}$ with the ME model if the outer pipe is hot in the identification of the DPHE. Table 4 also shows that the average of absolute error is $5.8 \%$ for $T_{c, \text { out }}$ with the $\mathrm{E}$ and ME models, $0.7 \%$ for $T_{h, \text { out }}$ with the $\mathrm{E}$ model and $0.5 \%$ for $T_{h, o u t}$ with the ME model if the outer pipe is cold in the identification of the DPHE. Table 5 shows that the average of absolute error is $1.0 \%$ for $T_{c, \text { out }}$ with the $\mathrm{E}$ and $\mathrm{ME}$ models and $1.5 \%$ for $T_{h, \text { out }}$ with the $\mathrm{E}$ and ME models for a single day (28 June, 2012) in the identification of the CPHE. These values are $1.1 \%$ and $1.5 \%$, respectively, for the whole identification (four days) of the CPHE.

Figs. 3 and 4 compare the measured and modelled outlet temperatures in the identification of the DPHE while Fig. 5 compares the measured and modelled outlet temperatures on a single day (28 June, 2012) of the identification of the CPHE. 
DPHE, outer pipe hot, inner pipe cold (identification)
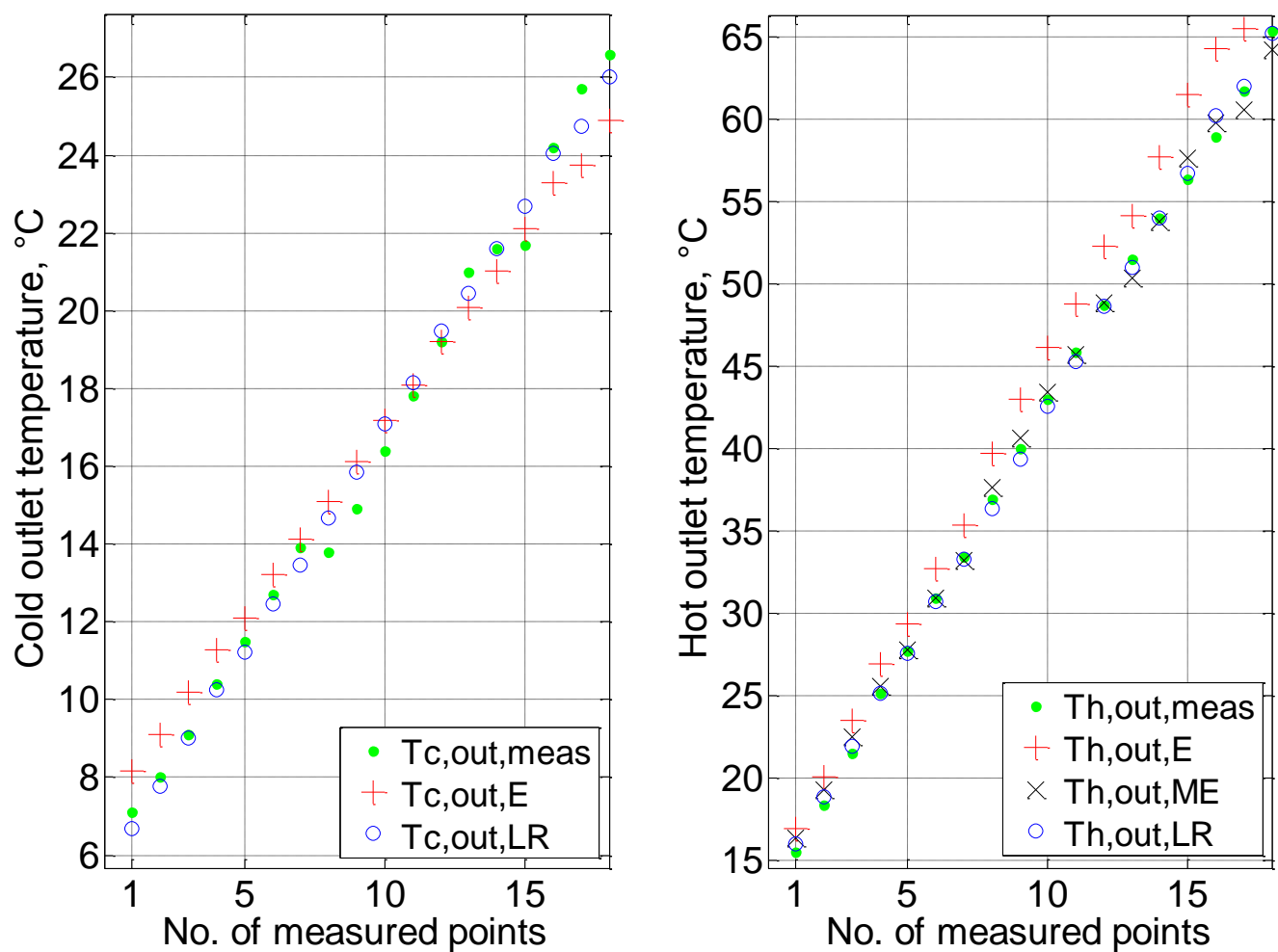

Fig. 3. Measured and modelled outlet temperatures in the identification of the DPHE when the outer pipe is hot

DPHE, outer pipe cold, inner pipe hot (identification)
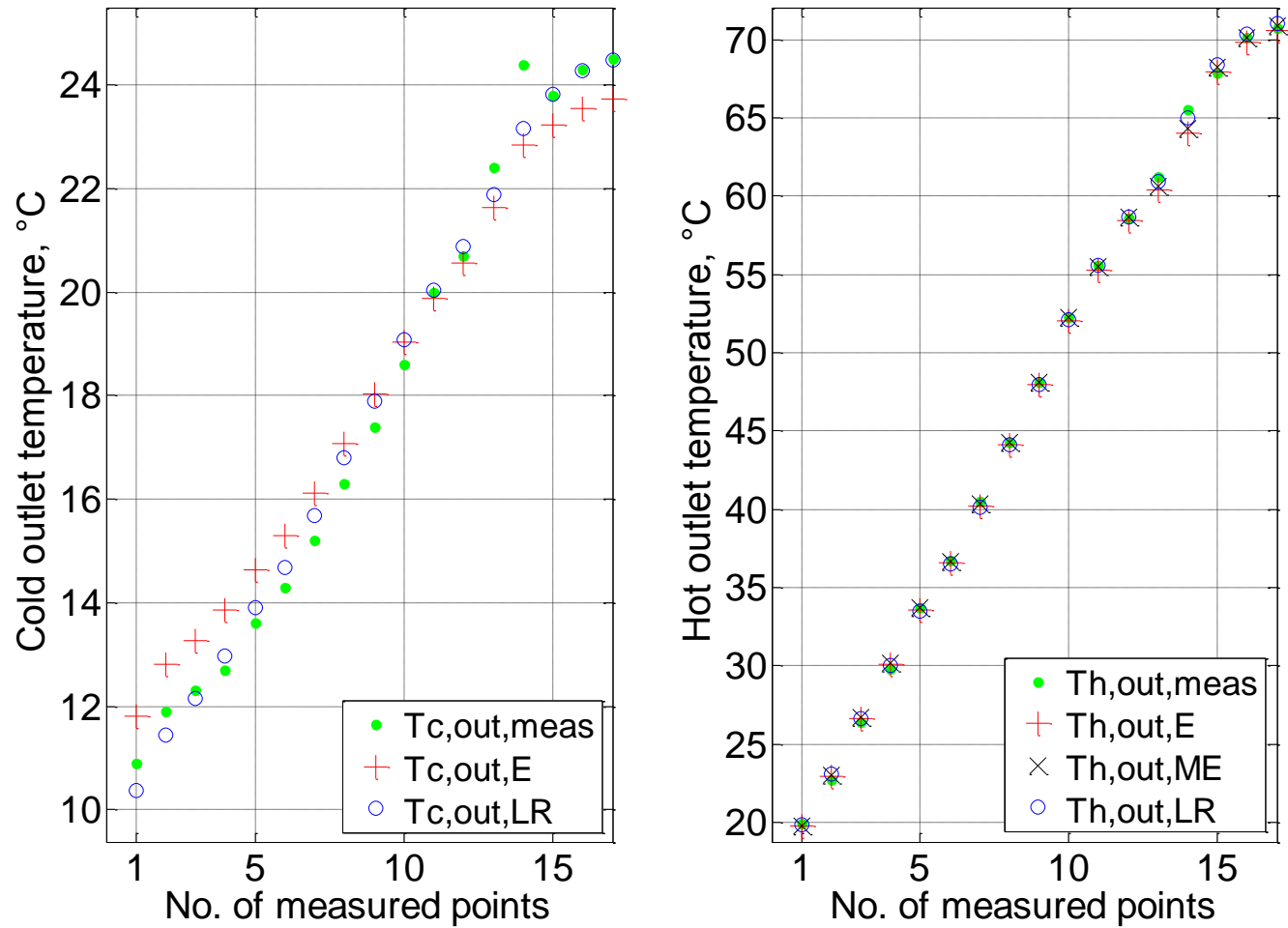

No. of measured points

Fig. 4. Measured and modelled outlet temperatures in the identification of the DPHE when the outer pipe is cold 

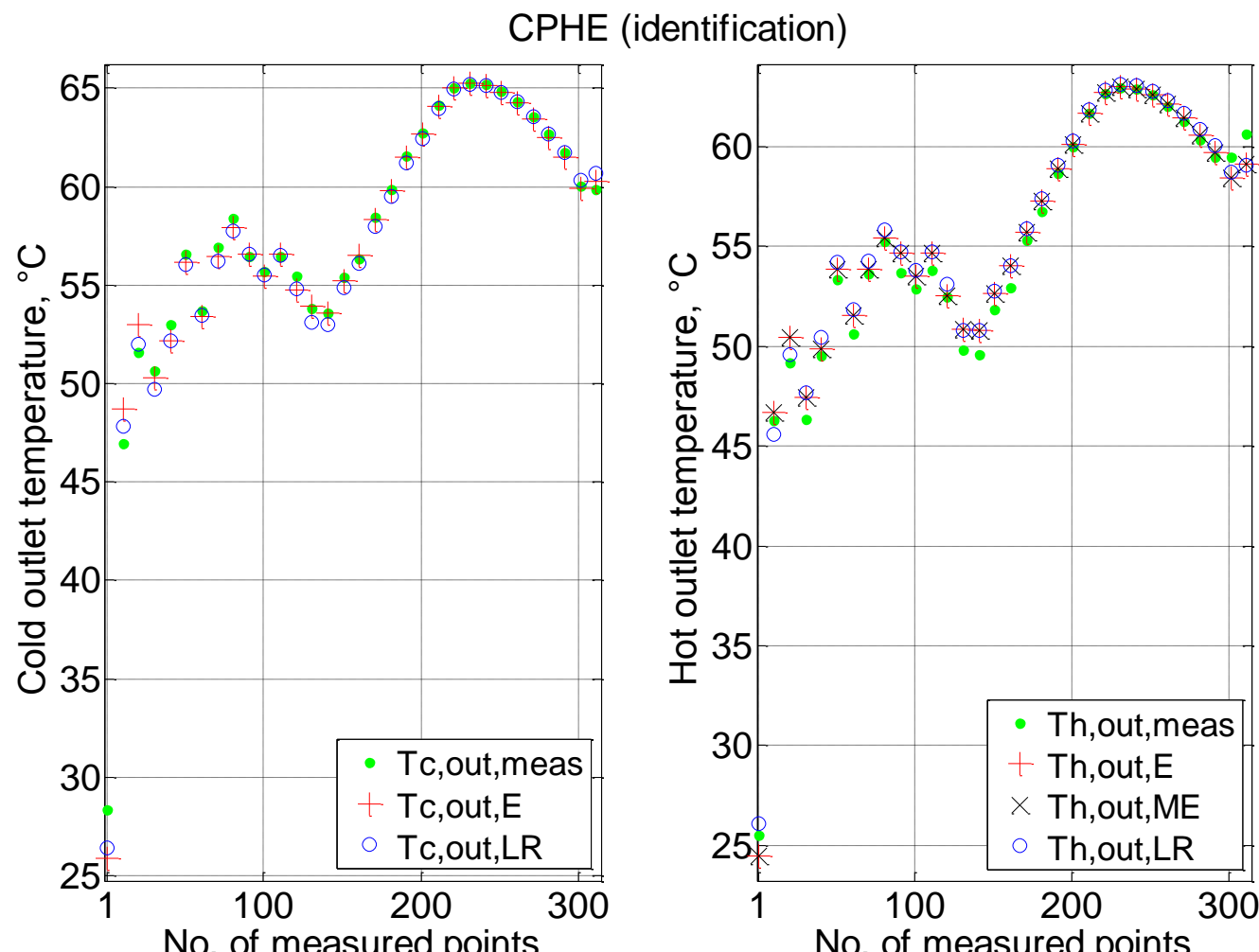

Fig. 5. Measured and modelled outlet temperatures on a single day (28 June, 2012) of the identification of the CPHE

With respect to $T_{c, \text { out }}$, the modelled results are the same with the $\mathrm{E}$ and ME models (since Eqs. (1a) and (2a) are the same), that is why the graph of the ME model is not contained in the corresponding part of Figs. 3, 4 and 5. For better visualization, the results of only every tenth measured time point is shown in Fig. 5. Although, the measured points are taken in increasing order (of real time) in the figures, the pause between the neighbouring points may be varying in Fig. 5 according to the intermittent operation of the real solar heating system of the CPHE.

\subsection{Validation}

The $\mathrm{E}$ and ME models with the identified $\Phi, m$ and measured $T_{c, i n}\left(t-\tau_{c}\right)$ and $T_{h, i n}\left(t-\tau_{h}\right)$ values are applied to model the outlet temperatures throughout the whole time of the validation. Then the results are compared with the measured outlet temperatures. Tables 4 and 5 present the indices of comparison. Table 4 shows that the average of absolute error is $4.9 \%$ for $T_{c, \text { out }}$ with the $\mathrm{E}$ and ME models, $5.9 \%$ for $T_{h, \text { out }}$ with the $\mathrm{E}$ model and $1.2 \%$ for $T_{h, \text { out }}$ with the ME model if the outer pipe is hot in the validation of the DPHE. Table 4 also shows that the average of absolute error is $6.0 \%$ for $T_{c, \text { out }}$ with the $\mathrm{E}$ and ME models, $0.6 \%$ for $T_{h, \text { out }}$ with the E model and $0.7 \%$ for $T_{h, \text { out }}$ with the ME model if the outer pipe is cold in the validation of the DPHE. Table 5 shows that the average of absolute error is $0.9 \%$ for $T_{c, \text { out }}$ with the $\mathrm{E}$ and ME models and $1.2 \%$ for $T_{h, \text { out }}$ with the E and ME models for a single day (3 August, 2012) in the validation of the CPHE. These values are $1.5 \%$ and $3.0 \%$, respectively, for the whole validation (56 days) of the CPHE.

Figs. 6 and 7 compare the measured and modelled outlet temperatures in the validation of the DPHE while Fig. 8 compares the measured and modelled outlet temperatures on a single day (3 August, 2012) of the validation of the CPHE. 
DPHE, outer pipe hot, inner pipe cold (validation)

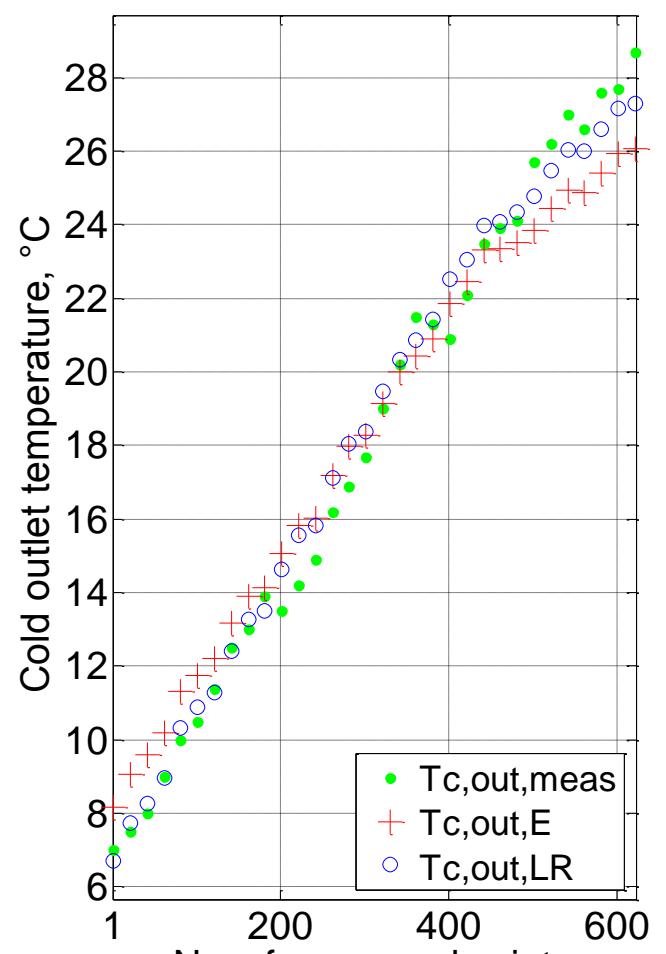

No. of measured points

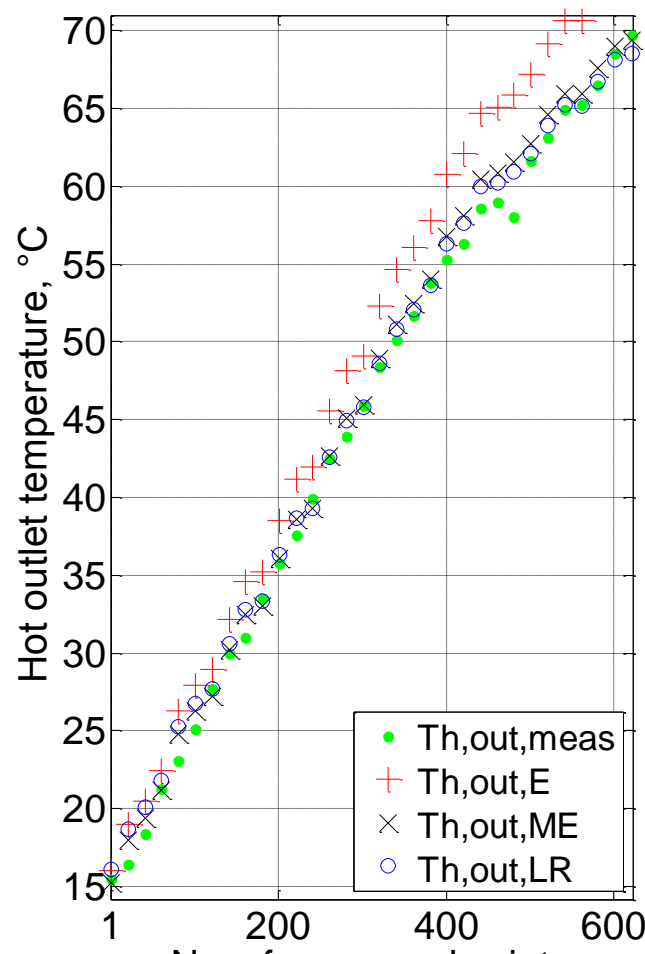

No. of measured points

Fig. 6. Measured and modelled outlet temperatures in the validation of the DPHE when the outer pipe is hot

DPHE, outer pipe cold, inner pipe hot (validation)
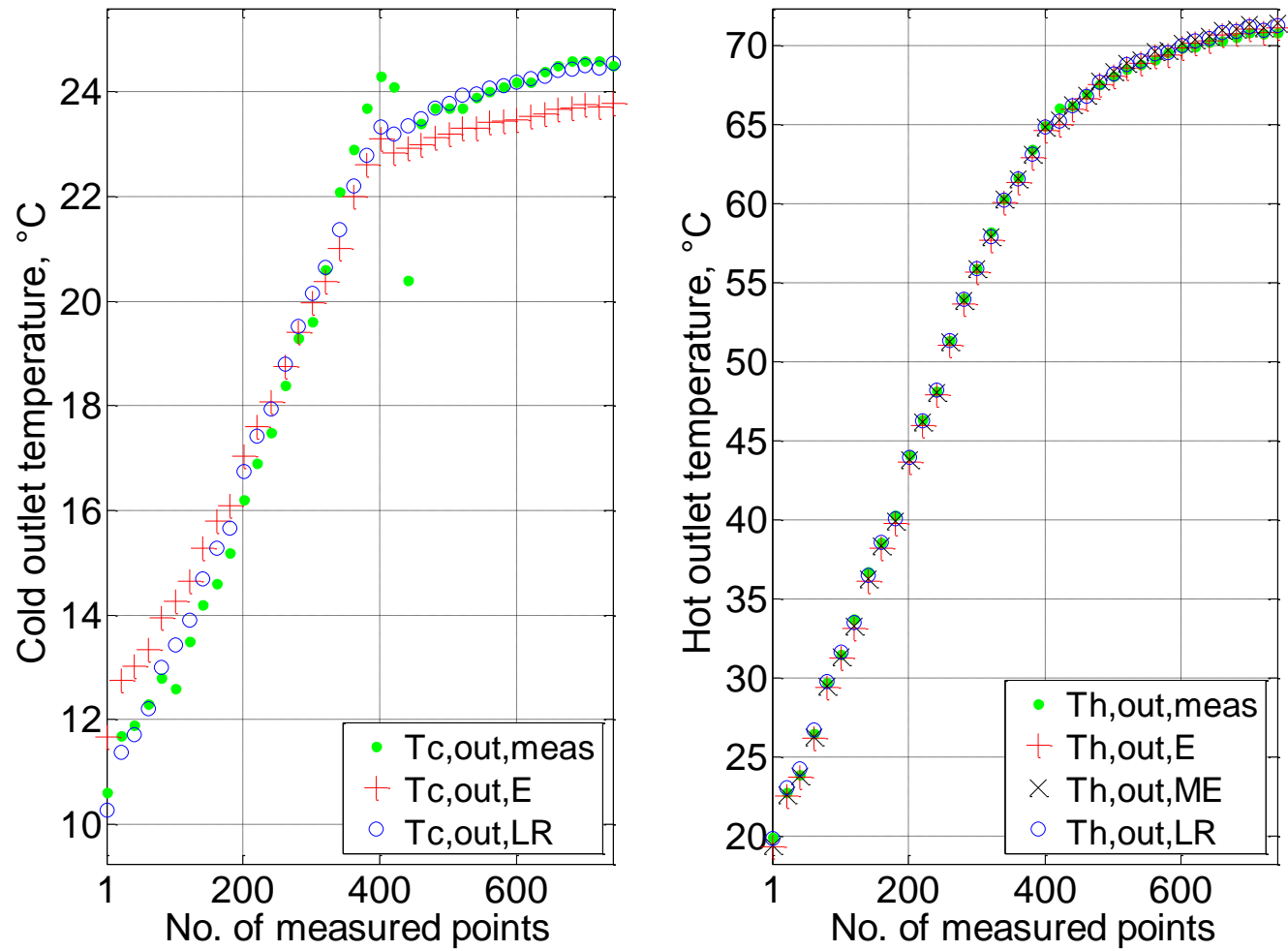

Fig. 7. Measured and modelled outlet temperatures in the validation of the DPHE when the outer pipe is cold 


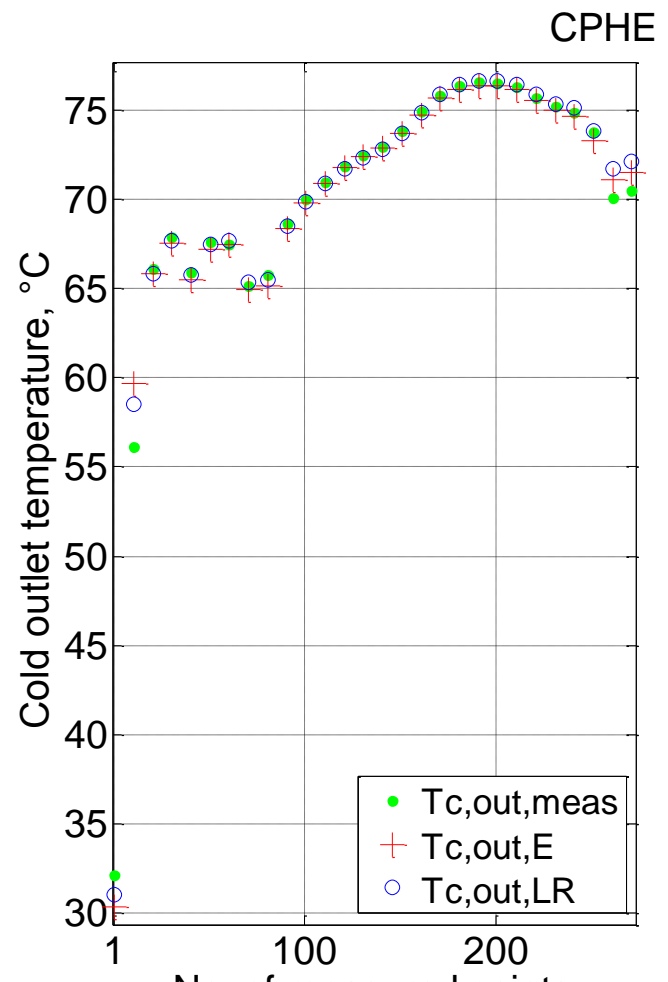

No. of measured points

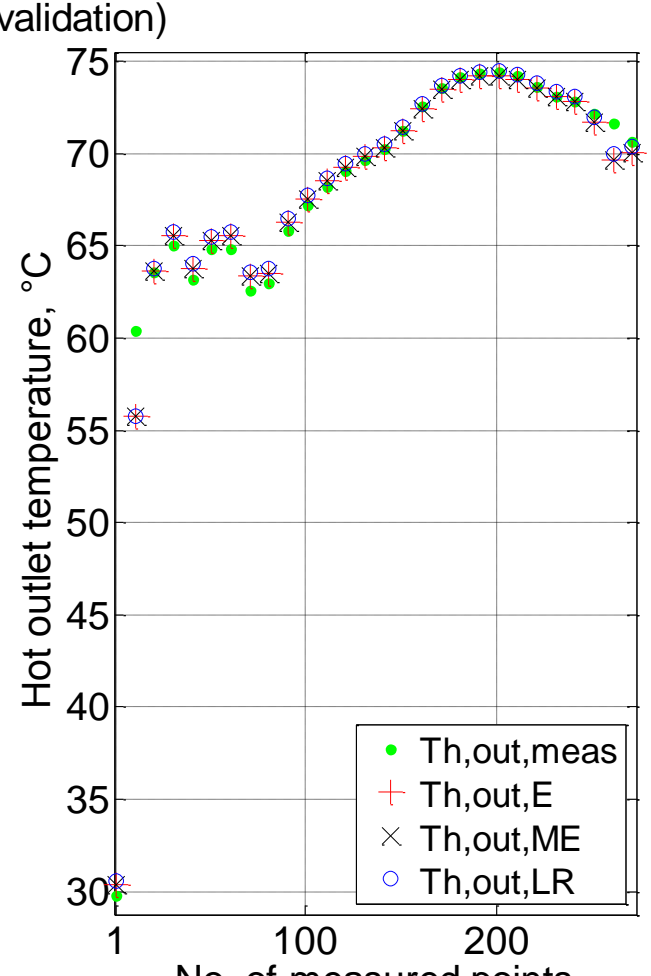

No. of measured points

Fig. 8. Measured and modelled outlet temperatures on a single day (3 August, 2012) of the validation of the CPHE

Regarding $T_{c, \text { out }}$, the graph of the ME model is omitted in the corresponding part of Figs. 6, 7 and 8 because of the mentioned coincidence with the $\mathrm{E}$ model. For better visualization, the results of only every twentieth measured time point is shown in Figs. 6 and 7, and the results of every tenth point is shown in Fig. 8. Although, the measured points are taken in increasing order (of time) in the figures, the pause between the neighbouring points may be varying in Fig. 8 according to the intermittent operation of the solar heating system contained the CPHE. On the face of Fig. 6, it can be stated that the ME model is more precise in predicting $T_{h, \text { out }}$ than the E model (the $\times$ marks are generally closer to the dots than the + marks) in case of the DPHE if the outer pipe is hot. Figs. 7 and 8 suggest that the $\mathrm{E}$ and ME models are essentially the same precise in case of the DPHE if the outer pipe is cold and in case of the CPHE.

\section{LR model}

The linear Eqs. (4a) and (4b) describe the LR model for heat exchangers generally.

$$
\begin{aligned}
& T_{c, \text { out }}(t)=c_{c, c, \text { in }} T_{c, \text { in }}\left(t-\tau_{c}\right)+c_{c, h, \text { in }} T_{h, \text { in }}\left(t-\tau_{h}\right), \\
& T_{h, \text { out }}(t)=c_{h, c, \text { in }} T_{c, \text { in }}\left(t-\tau_{c}\right)+c_{h, h, \text { in }} T_{h, \text { in }}\left(t-\tau_{h}\right)
\end{aligned}
$$

From $u_{T}=1{ }^{\circ} \mathrm{C}$, the uncertainty of the modelled $T_{c, \text { out }}$ and $T_{h, \text { out }}$ temperatures can be determined with Eqs. (3a) and (3b) for the LR model similarly as in case of the E and ME models in Section 3. The partial derivatives in Eqs. (3a) and (3b) can can be derived from the relations (4a) and (4b) in case of the LR model. The results can be found in Table 2.

\subsection{Identification}

In the LR model, the constant parameters to be identified are $c_{c, c, i n}, c_{c, h, i n}, c_{h, c, i n}$ and $c_{h, h, i n}$. Knowing the measured $T_{c, \text { in }}\left(t-\tau_{c}\right), T_{h, \text { in }}\left(t-\tau_{h}\right), T_{c, \text { out }}(t)$ and $T_{h, \text { out }}(t)$ values for the whole time period of the identification, the above four parameters can be easily identified with the application of a standard MLR routine, which is generally built in statistical and spreadsheet 
programs (see Excel, SPSS, etc.). In this exact way, $c_{c, c, i n}, c_{c, h, i n}, c_{h, c, i n}$ and $c_{h, h, i n}$ are not optional but unambiguously determined. In fact, they still depend on the measured values of the time period for the identification, nevertheless, with a given data base for the identification, they do not depend on the subjective thoughts of the user. Furthermore, the possible measurement-dependent (slight) deviation can be minimized with satisfactorily much data for the identification. The resulted (identified) values of $c_{c, c, i n}, c_{c, h, i n}, c_{h, c, \text { in }}$ and $c_{h, h, i n}$ can be found in Table 1.

Henceforth, the LR model (Eqs. (4a) and (4b)) with the identified parameters is applied to model the outlet temperatures throughout the whole identification. Tables 3, 4 and 5 present the indices of comparison with respect to the modelled and measured results. Table 3 contains the $R^{2}$ (square of correlation coefficient) values of the LR model for the identification. Table 4 shows that the average of absolute error is $2.4 \%$ for $T_{c, \text { out }}$ and $0.8 \%$ for $T_{h, \text { out }}$ with the LR model if the outer pipe is hot in the identification of the DPHE. Table 4 also shows that the average of absolute error is $2.6 \%$ for $T_{c, \text { out }}$ and $0.5 \%$ for $T_{h, \text { out }}$ with the LR model if the outer pipe is cold in the identification of the DPHE. Table 5 shows that the average of absolute error is $1.2 \%$ for $T_{c, \text { out }}$ and $2.0 \%$ for $T_{h, \text { out }}$ with the LR model for a single day (28 June, 2012) in the identification of the CPHE. These values are $1.1 \%$ and $1.6 \%$, respectively, for the whole identification (four days) of the CPHE.

Figs. 3 and 4 compare the measured and modelled outlet temperatures in the identification of the DPHE while Fig. 5 compares the measured and modelled outlet temperatures on a single day (28 June, 2012) of the identification of the CPHE.

\subsection{Validation}

The LR model with the identified $c_{c, c, i n}, c_{c, h, i n}, c_{h, c, i n}, c_{h, h, i n}$ and measured $T_{c, i n}\left(t-\tau_{c}\right)$ and $T_{h, \text { in }}\left(t-\tau_{h}\right)$ values are applied to model the outlet temperatures throughout the whole time of the validation. Then the results are compared with the measured outlet temperatures. Tables 4 and 5 present the indices of comparison. Table 4 shows that the average of absolute error is $2.8 \%$ for $T_{c, \text { out }}$ and $1.0 \%$ for $T_{h, \text { out }}$ with the LR model if the outer pipe is hot in the validation of the DPHE. Table 4 also shows that the average of absolute error is $2.6 \%$ for $T_{c, o u t}$ and $0.4 \%$ for $T_{h, \text { out }}$ with the LR model if the outer pipe is cold in the validation of the DPHE. Table 5 shows that the average of absolute error is $0.8 \%$ for $T_{c, \text { out }}$ and $1.4 \%$ for $T_{h, \text { out }}$ with the LR model for a single day (3 August, 2012) in the validation of the CPHE. These values are $1.5 \%$ and $3.3 \%$, respectively, for the whole validation (56 days) of the CPHE.

Figs. 6 and 7 compare the measured and modelled outlet temperatures in the validation of the DPHE while Fig. 8 compares the measured and modelled outlet temperatures on a single day (3 August, 2012) of the validation of the CPHE.

On the face of Fig. 6, it can be stated that the LR model is the most precise in predicting $T_{c, \text { out }}$ (the circles are closer to the dots than the + marks), the LR and ME models are essentially the same precise and more precise than the E model in predicting $T_{h, o u t}$ in case of the DPHE if the outer pipe is hot. Fig. 7 suggests that LR model is the most precise in predicting $T_{c, \text { out }}$ and all models are essentially the same precise in predicting $T_{h, \text { out }}$ in case of the DPHE if the outer pipe is cold. Fig. 8 suggests that all models are essentially the same precise in predicting both outlet temperatures in case of the CPHE.

\section{Comparison and discussion}

The validation results of Table 4 show that the LR model is considerably more precise than the $\mathrm{E}$ and ME models, that is it always has the lowest modelling error $(2.8 \%$ and $1.0 \%$ if the outer pipe is hot and $2.6 \%$ and $0.4 \%$ if the outer pipe is cold) in case of the DPHE. This may 
be explained with that the heat loss or heat gain between the heat exchanger and the environment is considerable in case of the DPHE, which makes the heat phenomena relating to a heat exchanger more complicated/complex, and, generally, simple black-box type models (like the LR model) may be able to describe complex physical processes better than simple physically-based models [23, 24, 25] (like the E model), since they work in a global, empirical way without dealing with the physical details. Accordingly, the ME model, which

can be considered as a partly empirical, partly physically-based model, predicts $T_{h, \text { out }}$ better (with an error of $1.2 \%$ ) than the purely physically-based E model (with 5.9\%), when the outer pipe is hot, that is if the heat loss of the outer pipe is relatively high (which can be seen from that the $m=1.27$ (see Table 1) is considerably higher than 1). If the outer pipe is cold and the interaction with the environment (heat gain) is lower ( $m=0.93$ is closer to 1$)$, the difference between the $\mathrm{E}$ and ME models in modelling $T_{h, \text { out }}$ is negligible (the error is $0.6 \%$ and $0.7 \%$, respectively).

In addition, the results of the LR model can be compared with the ones published in [26], where also linear relations have been derived for the outlet temperature of the cold side. More particularly, the comparison has been carried out for $T_{c, \text { out }}$ in case of DPHEs, under the following circumstances: hot fluid is in the inner pipe and both flow rates are constant but different (this is the case of the first nine rows in Table 1 of [26]). Based on Table 1 of [26] and Table 4 of the present study, the average of absolute error is 3.3\% in [26] and $2.6 \%$ with the LR model. While the precision of the compared models are essentially the same, the LR model based on linear regression is considerably easier to derive than the models worked out in [26], where complex physical relations and mathematical calculations (with iterative process) were needed to gain the proposed relations. Furthermore, thermodynamic properties (like the NTU) were needed to identify in [26] by means of a special heat exchanger simulator (because of the complex and iterative derivations of the thermodynamic properties). In the present study, as a clear advantage, the proposed linear relations ( $3 a$ and $b$ ) are very general needing no preliminary calculations, and, for the identification, only the standard MLR routine is needed, which can be found in basic statistical or spreadsheet programs (Excel, SPSS, etc.).

The validation results of Table 5 show that the E model (or the ME model) is not worse, even slightly more precise than the LR model, in case of the CPHE, which can be explained with that the interaction with the environment is negligible $(m=1)$ due to the relatively small exterior surface characterizing this kind of heat exchangers $\left(A_{e}<<A\right.$ in Table 1). This clear and relatively simple case (controlled energy balance between the two sides) is favourable to simple physically-based models (the E and ME models are the same in such a case).

In modelling $T_{c, \text { out }}$, the $\mathrm{E}$ and ME models perform the same for any heat exchangers, since they use the same equation (Eqs. (1a) and (2a)).

Table 2 shows that the uncertainty values of the models are nearly the same except the case of modelling $T_{c, \text { out }}$ of the DPHE, when $u_{c, \text { out }}\left(0.36{ }^{\circ} \mathrm{C}\right.$ and $\left.0.58{ }^{\circ} \mathrm{C}\right)$ is much lower with the LR model than the corresponding values $\left(\sim 0.8^{\circ} \mathrm{C}\right)$ with the other two models. This means that the LR model is considerably more efficient [32] than the other two models in predicting the outlet temperature of the cold side of the DPHE.

\section{Conclusion}

The well-tried and frequently used, physically-based E model (standing for the well-known effectiveness-NTU approach) with respect to heat exchangers has been recalled in the present study. This model assumes energy balance between the two sides of a heat exchanger. Based on studies in the literature, mathematical models with similar (linear, algebraic) simplicity to that of the E model, but under heat gain/loss to the environment, are still lacking in the field. This work has intended to contribute to filling this gap with the proposed ME and LR models. 
The partly empirical ME model (as the modified version of the E model) and the empirical, completely new (black-box type) LR model have been validated and compared with the E model based on measured data. These models are the same convenient to use as the E model, since the outlet temperatures can be explicitly expressed from the simple linear algebraic relations. The LR model can be considered as the natural continuation of the former works $[23,24]$, in the Conclusion of which it was suggested to work out MLR based models for different working components in hydraulic heating systems.

The comparison has shown that all three models are accurate enough for general engineering/modelling purposes, nevertheless, the LR model is always the most precise one (considerably more precise than the $\mathrm{E}$ and ME models) in modelling both $T_{c, \text { out }}$ and $T_{h, \text { out }}$ if the heat transfer between the heat exchanger and the environment is not negligible. This may be explained with that the interaction with the environment makes the heat phenomena more complicated/complex, and, generally, simple black-box type models (like the LR model) may be able to describe complex physical processes better than simple physically-based models. The ME model is also more accurate than the $\mathrm{E}$ model in predicting $T_{h, \text { out }}$ if the heat transfer to the environment is considerable, but, they have essentially the same precision if the environment has low effect. With respect to modelling $T_{c, \text { out }}$, the $\mathrm{E}$ and ME models are the same. The E model (or the ME model) is not worse, even slightly more precise than the LR model, if the interaction with the environment is negligible (for example, because of the relatively small exterior surface of the heat exchangers, as in case of a CPHE). It can be explained with that such a case makes the heat phenomena relatively clear and simple (controlled energy balance between the two sides), which is favourable to simple physicallybased models (the $\mathrm{E}$ and ME models are the same in such a case).

Table 2 shows that the uncertainty values of the models are nearly the same except the case of modelling $T_{c, \text { out }}$ of the DPHE, when the LR model is considerably more efficient than the other two models. This essentially reinforces the above conclusions.

Based on these results, the LR model can be recommended for precise modelling of the outlet temperatures of heat exchangers if the heat transfer with the environment is not negligible. This is the case if the exterior surface of the heat exchanger is not very small in comparison with the internal surface between the two sides, as in the important case of a DPHE. Further, the LR model is easy and fast to use because of that the standard MLR routine (for identification) is generally built in statistical and spreadsheet programs (Excel, SPSS, etc.).

Since MLR based models are likely the simplest possible models (because of the simple linear relations), which can still reach a very good accuracy, it is worth extending MLR based researches. For example, by means of connecting the already introduced models for solar collectors [23], pipes [24], storage tanks [25] and heat exchangers (in the present paper), an MLR based model for whole hydraulic heating systems might be established.

\section{Acknowledgement}

The second author thanks the staff of the Department of Mathematics (Institute of Environmental Systems, Faculty of Mechanical Engineering, SZIU) for the contribution and the Department of Physics and Process Control for the measured data.

This paper was supported by the János Bolyai Research Scholarship of the Hungarian Academy of Sciences.

\section{Conflict of interest}

The authors state that there is no conflict of interest.

\section{References}

1. Czemplik A (2015) Simple models of central heating system with heat exchangers in the quasistatic conditions. In: R. Moreno-Díaz, F. Pichler, A. Quesada-Arencibia (eds.) Computer Aided Systems Theory - EUROCAST 2015. Lecture Notes in Computer Science, vol. 9520, Springer, Cham, pp. 597-604. 
2. Fang H, Xia J, Lu A, Jiang Y (2014) An operation strategy for using a ground heat exchanger system for industrial waste heat storage and extraction. Build Simul 7(2):197-204.

3. Velmurugan K, Christraj W, Kulasekharan N, Elango T (2016) Performance study of a dualfunction thermosyphon solar heating system. Arab J Sci Eng 41(5):1835-1846.

4. Ghorab M, Entchev E, Yang L (2017) Inclusive analysis and performance evaluation of solar domestic hot water system (a case study). Alexandria Eng J 56(2):201-212.

5. Pacio JC, Dorao CA (2011) A review on heat exchanger thermal hydraulic models for cryogenic applications. Cryogenics 51:366-379.

6. Kays WM, London AL (1984) Compact heat exchangers. McGraw-Hill, New York

7. Bradley JC (2010) Counterflow, crossflow and concurrent flow heat transfer in heat exchangers: analytical solution based on transfer units. Heat Mass Transf 46(4):381-394.

8. Incropera FP, DeWitt DP, Bergman TL, Lavine AS (2010) Fundamentals of heat and mass transfer, 6th edn. John Wiley and Sons, Chichester

9. Buzás J, Farkas I, Biró A, Németh R (1998) Modelling and simulation of a solar thermal system. Math Comput Simulat 48:33-46.

10. Zachár A (2012) Investigation of natural convection induced outer side heat transfer rate of coiledtube heat exchangers. Int J Heat Mass Transfer 55:7892-7901.

11. Sammeta H, Ponnusamy K, Majid MA, Dheenathayalan K (2011) Effectiveness charts for counter flow corrugated plate heat exchanger. Simul Model Pract Th 19:777-784.

12. Buzás J, Farkas I (2000) Solar domestic hot water system simulation using blockoriented software. In: The 3rd ISES-Europe solar world congress (Eurosun 2000), Copenhagen, Denmark, CD-ROM Proceedings, p. 9.

13. Vera M, Liñán A (2010) Laminar counterflow parallel-plate heat exchangers: Exact and approximate solutions. Int J Heat Mass Transfer 53:4885-4898.

14. Ratna Raju L, Nandi TK (2017) Effective NTU of a counterflow heat exchanger with unbalanced flow and longitudinal heat conduction through fluid separating and outer walls. Appl Therm Eng 112:1172-1177.

15. Sahin B, Ust Y, Teke I, Erdem HH (2010) Performance analysis and optimization of heat exchangers: a new thermoeconomic approach. Appl Therm Eng 30:104-109.

16. Omidi M, Farhadi M, Jafari M (2017) A comprehensive review on double pipe heat exchangers. Appl Therm Eng 110:1075-1090.

17. Alquaity ABS, Al-Dini SA, Zubair SM (2013) Effectiveness-NTU relations for parallel flow heat exchangers: The effect of kinetic energy variation and heat leak from outside. Int J Refrig 36:15571569.

18. Krishna V, Hegde PG, Subramanian N, Seetharamu KN (2012) Effect of ambient heat-in-leak on the performance of a three fluid heat exchanger, for cryogenic applications, using finite element method. Int J Heat Mass Transfer 55:5459-5470.

19. Mathew B, Hegab H (2010) Application of effectiveness-NTU relationship to parallel flow microchannel heat exchangers subjected to external heat transfer. Int J Therm Sci 49:76-85.

20. Aminuddin M, Zubair SM (2017) Analytical solutions to counter-flow heat exchanger subjected to external heat flux and axial conduction. Int J Refrig 74:22-37.

21. Korzenszky P, Kurják Z, Géczi G (2013) Armfield HT31 tubular heat exchanger in the education. Hungarian Agr Eng 25:19-21.

22. Pourahmad P, Pesteei SM (2016) Effectiveness-NTU analyses in a double tube heat exchanger equipped with wavy strip considering various angles. Energy Convers Manage 123:462-469.

23. Kicsiny R (2016) Improved multiple linear regression based models for solar collectors. Renew Energy 91:224-232.

24. Kicsiny R (2017) Grey-box model for pipe temperature based on linear regression. Int J Heat Mass Transfer 107:13-20.

25. Kicsiny R (2018) Black-box model for solar storage tanks based on multiple linear regression. Renew Energy 125:857-865.

26. Laskowski R (2015) The black box model of a double-tube counter-flow heat exchanger. Heat Mass Transf 51(8):1111-1119.

27. Etter DM, Kuncicky D, Moore H (2004) Introduction to MATLAB 7. Springer

28. https://mathtab.com/app_id=1 (July 2018)

29. http://www.sondexaustralia.com.au/products/heat-exchangers/plate-frame-heat-exchangers/ (July 2018) 
30. Kicsiny R (2017) Transfer functions of solar heating systems with pipes for dynamic analysis and control design. Sol Energy 150:596-607.

31. Kline SJ, McClintock FA (1953) Describing uncertainties in single sample experiments. Mech Eng $75: 3-8$.

32. McFadden D (2000) Statistical tools for economists. Department of Economics, University of California, Berkeley 